\title{
Ten-year changes in the prevalence of overweight, obesity and central obesity among the Chinese adults in urban Shanghai, 1998-2007 - comparison of two cross-sectional surveys
}

\author{
Xuhong Hou, Yu Liu, Huijuan Lu, Xiaojing Ma, Cheng Hu, Yuqian Bao and Weiping Jia*
}

\begin{abstract}
Background: In China, obesity is expected to increase rapidly in both urban and rural areas. However, there have been no comprehensive reports on secular trends in obesity prevalence among Chinese adults in urban Shanghai, which is the largest city in southern China.

Methods: In 1998-2001 and again in 2007-2008, two independent population-based cross-sectional surveys were conducted in Shanghai to investigate the prevalence of metabolic disorders. These surveys obtained height, waist circumference (WC), and weight measurements for Chinese adults aged between 20 and 74 years who lived in urban communities. From the 1998-2001 survey, 4,894 participants (2,081 men and 2,813 women, mean age: 48.9 years) were recruited, and 4,395 participants (1,599 men and 2,796 women, mean age: 49.8 years) were recruited from the 2007-2008 survey. Using the World Health Organization criteria, overweight was defined as $25 \mathrm{~kg} / \mathrm{m}^{2} \leq \mathrm{BMl}<30 \mathrm{~kg} / \mathrm{m}^{2}$ and obesity as BMI $\geq 30 \mathrm{~kg} / \mathrm{m}^{2}$. Central obesity was defined as $W C \geq 90 \mathrm{~cm}$ in men or $\geq 85 \mathrm{~cm}$ in women. The differences in prevalence of obesity, central obesity and overweight between the two surveys were tested using multivariable logistic regression analyses.
\end{abstract}

Results: Compared to the 1998-2001 survey, in the 2007-2008 survey the BMI distribution for men and the WC distribution for both genders is shifted significantly to the right along the $x$-axis (all $p<0.001$ ). Over the ten years, the prevalence of combined overweight and obesity increased $24 \%$ (from $31.5 \%$ to $39.1 \%, p<0.001$ ) in men, but decreased $8 \%$ (from $27.3 \%$ to $25.0 \% ; p<0.01$ ) in women. The prevalence of central obesity increased $40 \%$ in men (from $19.5 \%$ to $27.3 \% ; p<0.01$ ), but the increase was not significant in women $(15.0 \%$ to $17.1 \% ; p=0.051$ ). In the total population, only central obesity showed a significant change between the populations in the two surveys, increasing 29\% (from $17.3 \%$ to $22.4 \% ; p<0.001$ ).

Conclusions: Over this 10 year period, central obesity increased significantly in the Shanghai adult population. However, the prevalence of combined overweight and obesity was significantly increased in men but not in women.

Keywords: Central obesity, Chinese adults, Cross-sectional survey, Overweight, Obesity, Prevalence, Urban

\footnotetext{
* Correspondence: wpjia@sjtu.edu.cn

Department of Endocrinology and Metabolism, Shanghai Jiao Tong

University Affiliated Sixth People's Hospital, Shanghai Clinical Center for

Diabetes, Shanghai Diabetes Institute, Shanghai Key Laboratory of Diabetes

Mellitus, Shanghai Key Clinical Center for Metabolic Disease, 600 Yishan

Road, Shanghai 200233, China
} 


\section{Background}

In recent years, the prevalence of obesity in China has reached epidemic proportions, following rapid economic development and urbanization [1-3]. As obesity is an important and fundamental risk factor for cardiometabolic disorders, cardiovascular diseases and premature mortality [4-6], depicting the changing trends in obesity helps comprehend the prevalence of obesity-related chronic diseases and allows us to alert and inform the care professionals and the public in an attempt to prevent the epidemic. Body mass index (BMI) and waist circumference (WC) measurements are two important and practical indices that are used to identify general or central obesity, both in clinical practice and epidemiologic research. In general, central obesity is more closely associated with diabetes, whereas general obesity is more closely related with hypertension [5,7-10]. In addition, it has been reported that in some populations the mean WC is increasing more rapidly than mean BMI, especially in women, despite the fact that general obesity rates are stable or declining [11-15].

Shanghai is the largest city in southern China, and has recently experienced the most rapid economic development of mainland China. In Shanghai, we carried out two representative population-based cross-sectional surveys at an interval of approximately 10 years. These surveys, the 1998-2001 survey and the 2007-2008 survey, were designed to investigate the prevalence of metabolic disorders, and their protocols required the heights, weights, and waist circumferences of Chinese adults in Shanghai to be measured, allowing comparisons to be made in the changes in obesity measurements in this urban population over time. In the last decade, there have been no other comprehensive reports on the changing trends in the population prevalence of overweight, obesity or central obesity in urban Shanghai adults.

This study explores the secular changes in the prevalence of overweight, obesity and central obesity in Chinese adults in urban Shanghai by comparing two crosssectional surveys that were carried out at an interval of ten years.

\section{Methods}

This study was approved by the institutional review board of Shanghai Jiao Tong University Affiliated Sixth People's Hospital, in accordance with the principles of the Helsinki Declaration II. Written informed consents were obtained from each participant.

\section{Study population}

We analyzed datasets taken from two cross-sectional surveys with multistage sampling schemes carried out in Shanghai. The two surveys were designed to investigate the prevalence of metabolic disorders among Chinese adults.
In 1998-2001, the Shanghai Diabetes Study (SHDS) examined a total of 5994 participants aged 15 to 95 years old from two urban communities in Shanghai, Huyang and Caoyang [16]. In 2007-2008, SHDS II surveyed a total of 5289 participants aged 20 to 74 years from six communities: four urban communities, Huayang, Linfeng, Tianmu, and Pengpu; one suburban community, Gongye; and one rural community, Anting [17]. The response rates were approximately $95 \%$ for both surveys $[16,17]$. These two survey populations did not overlap, as, in general, they involved different communities; the Huayang community was included in both studies, but different residential areas were investigated in each study. The following criteria were required for inclusion in the study: age 20-74 years; living in an urban or suburban community; complete data available for both WC and BMI. From the 1998-2001 survey, 4,894 participants (2,081 men and 2,813 non-pregnant women, mean age: 48.9 years) were selected for analysis, and 4,395 participants (1,599 men and 2,796 non-pregnant women, mean age: 49.8 years) were selected from the 2007-2008 survey. Both these two study populations have been described in our previous papers $[16,17]$.

\section{Laboratory assessment of blood samples}

As described previously, after 10 hours of overnight fasting, venous blood samples were drawn from participants without self-reported diabetes at 0 and 120 minutes after ingestion of a $75 \mathrm{~g}$ oral glucose load. Plasma glucose levels were measured using the glucose oxidase method $[16,17]$. Serum cholesterol and triglyceride levels were determined using different enzymatic assays in each of the two studies [16,17]. All laboratory measurements complied with a standardized and certified program; the details have been described previously $[16,17]$.

\section{Physical examinations}

Blood pressure, body weight, and height were measured according to standard protocols [18]. Body weight, height and WC were measured once for each survey. Height, WC, and weight were measured while the participants were barefoot and in light clothing using the Height \& Weight Scale to the nearest $0.1 \mathrm{~cm}$ and $0.1 \mathrm{~kg}$, respectively. BMI was calculated as weight divided by height squared $\left(\mathrm{kg} / \mathrm{m}^{2}\right)$. WC was measured at the horizontal plane between the inferior costal margin and the iliac crest on the mid-axillary line.

Demographic data on lifestyle, disease history, and family history of disease, smoking and drinking habits were collected during the survey using standardized questionnaires. The family history of obesity obtained information about obesity in first-degree relatives (biological mother, father, brothers, or sisters). Current smokers were defined as those who had smoked $\geq 1$ cigarette/day for at least 1 year. Current drinkers were defined as those who had 
consumed $\geq 30 \mathrm{~g}$ of alcohol/week on average for at least 1 year. The educational level of participants was also recorded and categorized into three groups: low (illiterate, or having only attended primary and secondary education); medium (high school educated) and high (college or university educated). Monthly household income was classified as low level $(<1000$ yuan RMB), medium level (1000-3000 yuan RMB), or high level ( $\geq 3000$ yuan RMB).

\section{Definitions of obesity}

Overweight and Obesity Two standards were used to diagnose overweight and obesity. Overweight is defined as $\mathrm{BMI} \geq 25 \mathrm{~kg} / \mathrm{m}^{2}$ and $<30 \mathrm{~kg} / \mathrm{m}^{2}$ and obesity as $\mathrm{BMI} \geq$ $30 \mathrm{~kg} / \mathrm{m}^{2}$ using the World Health Organization (WHO) standards [19]. Using the Working Group on Obesity in China (WGOC) criteria, overweight is defined as a BMI between $24 \mathrm{~kg} / \mathrm{m}^{2}$ and $28 \mathrm{~kg} / \mathrm{m}^{2}$ and obesity as BMI $\geq$ $28 \mathrm{~kg} / \mathrm{m}^{2}$ [20].

Central Obesity Central obesity is $\mathrm{WC} \geq 90 \mathrm{~cm}$ in men and $\geq 85 \mathrm{~cm}$ in women, as defined by the Chinese Joint Committee for Developing Chinese Guidelines on Prevention and Treatment of Dyslipidemia in Adults (JCDCG) [21].

\section{Statistical analysis}

Descriptive statistics are presented as the mean ( \pm standard deviation) or frequency (percentage). Age-adjusted $p$ values for differences between means were calculated using covariance analyses (except for the non-adjusted p-value for age mean), or using multivariable logistic regression analyses for variables expressed as proportions (Table 1).

Standardized means and percentages were calculated using the direct method according to the Chinese population structure in 2000 [22] (Table 2, Figure 1, and Additional file 1: Table S1). Potential differences in ageadjusted means between the two surveys in both men and women were tested using covariance analyses (univariate general linear model, age-adjusted). Linear trends for age-specific means were tested using linear regression analyses, with age group being treated as a continuous variable (Table 2).

Potential differences in standardized proportions (prevalence) between the two surveys were tested using multivariable logistic regression analyses in men or women (adjusted for age), and among all participants (adjusted for sex and age), using the Entry method. Adjusted odds ratios (AORs) and $\mathrm{p}$ values were then calculated (Figure 1).

In addition, linear trends for proportions were tested using logistic regression analyses; again, age group was treated as a continuous variable. Differences in proportions (age-adjusted) between the two surveys in both men and women were tested using an age-adjusted multivariable logistic regression analysis (Additional file 1: Table S1).

All statistical analyses were performed using SPSS version 15.0 (SPSS Inc., Chicago, IL, USA). $\mathrm{p}<0.05$ (twotailed) was designated as statistically significant. Curve fitting and lowess smoothing were performed using Matalab2007a.

The frequency distribution of BMI and waist circumference from the two surveys were smoothed using curve fitting with Matalab2007a, which is to construct a polynomial $\mathrm{P}(\mathrm{X})$ of degree $\mathrm{N}$ that fits the data $\mathrm{Y}$ best in a least-squares sense. The differences in the frequency distribution from the two surveys were tested with the Mann-Whitney $U$-test.

\section{Results}

Characteristics of Chinese adults in urban Shanghai aged 20-74 years in the 1998-2001 survey and in the 20072008 survey

The demographic and clinical characteristics of the men and women of both surveys are presented in Table 1 . The mean WCs and mean waist-to-height ratios (a measure of waist circumference relative to height) were both higher in men and women in the 2007-2008 survey, as compared with the 1998-2001 survey, but there was no betweensurvey change in waist-to-hip ratios in either men or women. In men, the mean BMI was higher in the 20072008 survey, as compared to the 1998-2001 survey: $24.2 \mathrm{~kg} / \mathrm{m}^{2}$ vs. $23.7 \mathrm{~kg} / \mathrm{m}^{2},(\mathrm{p}<0.001)$. Both genders had significantly higher mean fasting plasma glucose levels and $2 \mathrm{~h}$ post-load glucose levels ( $2 \mathrm{hPG}$ ) in the 2007-2008 survey $(\mathrm{p}<0.001)$; however, mean diastolic blood pressures (DBP) and mean lipid levels, apart from a decreased HDL$C$ level in men, were improved in the 2007-2008 survey $(\mathrm{p}<0.01)$ (Table 1).

In the 2007-2008 survey, the participants noted a significant increase in the family history of obesity than in the 1998-2001 survey. Between the two surveys, there were favorable changes in smoking habits for women and adverse changes in drinking habits for men. Although improvements in income were observed in both genders, improvement in education was only apparent in women.

\section{BMI and WC frequency distributions in the 1998-2001 and 2007-2008 surveys}

Figure 1 shows the frequency distributions of BMI and WC for men and women in 1998-2001 and in 20072008. Compared to the 1998-2001 survey, in the 20072008 survey the distribution of BMI for men is shifted significantly to the right along the $x$-axis, and the WC distribution is shifted to the right for both genders (all $\mathrm{p}$ $<0.001)$. There was no significant increase in median BMI in women $\left(23.4 \mathrm{~kg} / \mathrm{m}^{2}\right.$ to $\left.23.4 \mathrm{~kg} / \mathrm{m}^{2}, \mathrm{p}=0.554\right)$. 
Table 1 Characteristics of Shanghai urban Chinese adults aged 20-74 years in 1998-2001 and 2007-2008

\begin{tabular}{|c|c|c|c|c|c|c|}
\hline \multirow[b]{2}{*}{ Characteristic } & \multicolumn{3}{|c|}{ Men } & \multicolumn{3}{|c|}{ Women } \\
\hline & $\begin{array}{l}1998-2001 \\
(N=2081)\end{array}$ & $\begin{array}{l}2007-2008 \\
(\mathrm{~N}=1599)\end{array}$ & $p$ value & $\begin{array}{l}1998-2001 \\
(N=2813)\end{array}$ & $\begin{array}{l}2007-2008 \\
(N=2796)\end{array}$ & $p$ value \\
\hline \multicolumn{7}{|l|}{ Mean (SD) } \\
\hline Age (years) & $48.9(15.1)$ & $50.1(14.3)$ & 0.005 & $48.9(14.1)$ & $49.7(12.6)$ & $<0.001$ \\
\hline Height (cm) & $169.3(6.5)$ & $169.3(6.4)$ & 0.397 & $157.5(6.2)$ & $158.3(5.8)$ & $<0.001$ \\
\hline BMI $\left(\mathrm{kg} / \mathrm{m}^{2}\right)$ & $23.7(3.4)$ & $24.2(3.3)$ & $<0.001$ & 23.8 (3.6) & $23.7(3.4)$ & 0.148 \\
\hline Waist circumference $(\mathrm{cm})$ & $82.3(9.9)$ & $84.9(9.3)$ & $<0.001$ & $76.9(10.0)$ & $78.2(9.3)$ & $<0.001$ \\
\hline Waist-to-height ratio & $0.49(0.1)$ & $0.50(0.1)$ & $<0.001$ & $0.49(0.1)$ & $0.50(0.1)$ & 0.017 \\
\hline Waist-to-hip ratio & $0.89(0.07)$ & $0.89(0.06)$ & 0.107 & $0.83(0.08)$ & $0.84(0.13)$ & 0.748 \\
\hline SBP $(\mathrm{mmHg})$ & $125.5(18.4)$ & $124.5(15.9)$ & 0.008 & $121.9(19.8)$ & $120.4(16.7)$ & 0.660 \\
\hline $\mathrm{DBP}(\mathrm{mmHg})$ & $81.1(10.9)$ & $79.4(10.0)$ & 0.005 & $77.6(10.3)$ & $75.8(9.4)$ & $<0.001$ \\
\hline TC (mmol/L) & $4.88(1.10)$ & $4.55(0.91)$ & $<0.001$ & $5.04(1.18)$ & $4.72(0.98)$ & $<0.001$ \\
\hline TG $(\mathrm{mmol} / \mathrm{L})$ & $1.99(1.57)$ & $1.91(1.59)$ & $<0.001$ & $1.73(1.12)$ & $1.55(1.20)$ & $<0.001$ \\
\hline HDL-C (mmol/L) & $1.26(0.28)$ & $1.19(0.29)$ & $<0.001$ & $1.34(0.29)$ & $1.39(0.31)$ & $<0.001$ \\
\hline LDL-C (mmol/L) & $3.34(0.98)$ & $2.94(0.77)$ & $<0.001$ & $3.43(1.07)$ & $2.98(0.81)$ & $<0.001$ \\
\hline FPG (mmol/L) & $5.29(1.51)$ & $5.68(1.76)$ & $<0.001$ & $5.25(1.34)$ & $5.47(1.34)$ & $<0.001$ \\
\hline $2 \mathrm{hPG}(\mathrm{mmol} / \mathrm{L})^{\mathrm{a}}$ & $5.43(1.71)$ & $6.08(1.63)$ & $<0.001$ & $5.56(1.5)$ & $6.12(1.51)$ & $<0.001$ \\
\hline \multicolumn{7}{|l|}{$n(\%)$} \\
\hline Family history of obesity & $241(12.9)$ & $262(17.3)$ & $<0.001$ & $350(13.9)$ & $517(19.1)$ & $<0.001$ \\
\hline Smoking status & & & 0.376 & & & 0.003 \\
\hline Non-smoker & $738(39.4)$ & $619(38.7)$ & & $2436(96.7)$ & $2746(98.2)$ & \\
\hline Current smoker & $986(52.7)$ & $837(52.3)$ & & $75(3)$ & $44(1.6)$ & \\
\hline Ex-smoker & $147(7.9)$ & $143(8.9)$ & & $8(0.3)$ & $6(0.2)$ & \\
\hline Dinking status & & & $<0.001$ & & & 0.314 \\
\hline Non-drinker & $1364(72.7)$ & $1050(65.7)$ & & 2479 (98.2) & 2728 (97.6) & \\
\hline Current drinker & $506(27)$ & $494(30.9)$ & & $43(1.7)$ & $63(2.3)$ & \\
\hline Ex-drinker & $5(0.3)$ & $55(3.4)$ & & $3(0.1)$ & $5(0.2)$ & \\
\hline Education & & & 0.046 & & & 0.021 \\
\hline Low & $726(38.8)$ & $663(42.4)$ & & $1409(56.0)$ & $1421(51.9)$ & \\
\hline Medium & $685(36.6)$ & $555(35.5)$ & & $815(32.4)$ & $932(34.0)$ & \\
\hline High & $459(24.5)$ & $347(22.2)$ & & $290(11.5)$ & $387(14.1)$ & \\
\hline Income levels & & & $<0.001$ & & & $<0.001$ \\
\hline Low & $332(17.7)$ & 198 (13.2) & & 499 (19.8) & $393(15.1)$ & \\
\hline Medium & $1164(62.2)$ & $652(43.5)$ & & $1644(65.1)$ & 1195 (45.9) & \\
\hline High & $375(20.0)$ & $648(43.3)$ & & $382(15.1)$ & 1014 (39.0) & \\
\hline
\end{tabular}

Data are expressed as means (standard deviations) or as frequencies (\%).

p-values (adjusted for age) for differences between means were calculated using a covariance analysis (ANCOVA, apart from the non-adjusted p-value for age), or using multivariable logistic regression analyses with variables shown as proportions.

a 2 hPG was assessed in participants not known to have diabetes.

Abbreviations: BMI: body mass index; DBP: diastolic blood pressure; FPG: fasting plasma glucose; HDL-C: high density lipoprotein cholesterol; LDL-C: low density lipoprotein cholesterol; SBP: systolic blood pressure; TC: total cholesterol; TG: triglyceride; 2 hPG: $2 \mathrm{~h}$ post-load plasma glucose.

BMIs and WCs in the 1998-2001 and 2007-2008 surveys Table 2 shows significant increases in mean BMI $\left(0.5 \mathrm{~kg} / \mathrm{m}^{2}, \mathrm{p}<0.001\right)$ for men, and for mean WC in both genders $(2.6 \mathrm{~cm}$ for men and $1.3 \mathrm{~cm}$ for women, both $\mathrm{p}<0.001$ ) over the ten-year period. The standardized mean BMI in men increased from $23.5 \mathrm{~kg} / \mathrm{m}^{2}$ in the
$1998-2001$ survey to $24.1 \mathrm{~kg} / \mathrm{m}^{2}$ in the $2007-2008$ survey $(\mathrm{p}<0.001)$, but it was not significantly different between the women in these two populations $\left(23.1 \mathrm{~kg} / \mathrm{m}^{2}\right.$ in 2007-2008 vs. $23.0 \mathrm{~kg} / \mathrm{m}^{2}$ in $1998-2001 ; \mathrm{p}=0.148$ ). In addition, the standardized mean WC was $77.7 \mathrm{~cm}$ in the 1998-2001 survey vs. $79.9 \mathrm{~cm}$ in the 2007-2008 
Table 2 Standardized means of body mass index and waist circumference in 1998-2001 and 2007-2008

\begin{tabular}{|c|c|c|c|c|c|c|c|c|}
\hline \multirow[t]{2}{*}{ Population } & \multirow{2}{*}{$\begin{array}{c}N_{1} \\
1998-2001\end{array}$} & \multirow{2}{*}{$\begin{array}{c}N_{2} \\
2007-2008\end{array}$} & \multicolumn{3}{|c|}{ BMI $\left(\mathrm{kg} / \mathrm{m}^{2}\right)$} & \multicolumn{3}{|c|}{ Waist circumference $(\mathrm{cm})$} \\
\hline & & & $1998-2001$ & $2007-2008$ & Difference $^{\mathrm{e}}$ & 1998-2001 & 2007-2008 & Difference $^{\mathrm{e}}$ \\
\hline \multicolumn{9}{|l|}{ Standardized } \\
\hline Overall ${ }^{\mathrm{a}}$ & 4894 & 4395 & 23.3 & 23.6 & 0.2 & 77.7 & 79.9 & 1.4 \\
\hline$M^{\prime b}{ }^{b}$ & 2081 & 1599 & 23.5 & 24.1 & 0.5 & 81.1 & 83.9 & 2.6 \\
\hline Women $^{\mathrm{b}}$ & 2813 & 2796 & 23.0 & 23.1 & -0.1 & 74.1 & 75.7 & 1.3 \\
\hline$p$ values for difference ${ }^{c}$ & & & 0.257 & $p<0.001$ & & $p<0.001$ & $p<0.001$ & \\
\hline \multicolumn{9}{|l|}{ Sex- and age-specific } \\
\hline \multicolumn{9}{|l|}{ Men } \\
\hline 20-29 years & 225 & 199 & $23.3(4.2)$ & $23.3(3.8)$ & 0 & $78.3(11.1)$ & $80.2(10.7)$ & 1.9 \\
\hline 30-39 years & 406 & 235 & $23.2(3.3)$ & $24.3(3.5)$ & 1.1 & $80.4(9.3)$ & $83.5(8.9)$ & 3.1 \\
\hline $40-49$ years & 522 & 282 & $23.3(3.1)$ & $24.7(3.1)$ & 1.4 & $81.7(9.4)$ & $86.6(8.7)$ & 4.9 \\
\hline $50-59$ years & 284 & 457 & $24.1(3.1)$ & $24.4(3.2)$ & 0.3 & $83.9(9.5)$ & $85.8(8.8)$ & 1.9 \\
\hline $60-74$ years & 644 & 426 & $24.2(3.2)$ & $24.2(3.0)$ & 0 & $84.8(9.5)$ & $85.8(9.0)$ & 1 \\
\hline$p$ values for linear trend $d^{d}$ & & & $p<0.001$ & 0.058 & & $p<0.001$ & $p<0.001$ & \\
\hline \multicolumn{9}{|l|}{ Women } \\
\hline 20-29 years & 225 & 249 & $21.2(3.0)$ & $21.6(3.1)$ & 0.4 & $67.6(7.7)$ & $70.8(7.8)$ & 3.2 \\
\hline $30-39$ years & 561 & 427 & $22.8(3.4)$ & $22.8(3.3)$ & 0 & $73.0(8.4)$ & $73.8(8.3)$ & 0.8 \\
\hline 40-49 years & 841 & 590 & $23.5(3.2)$ & $23.8(3.2)$ & 0.3 & $75.5(8.3)$ & $78.2(8.5)$ & 2.7 \\
\hline $50-59$ years & 385 & 968 & $24.5(3.5)$ & $24.1(3.4)$ & -0.4 & $79.0(9.2)$ & $79.8(8.7)$ & 0.8 \\
\hline $60-74$ years & 801 & 562 & $25.2(3.7)$ & $24.5(3.5)$ & -0.7 & $82.8(9.9)$ & $82.0(9.0)$ & -0.8 \\
\hline$p$ values for linear trend ${ }^{d}$ & & & $p<0.001$ & $p<0.001$ & & $p<0.001$ & $p<0.001$ & \\
\hline
\end{tabular}

Data are expressed as the means (with standard deviations).

Means were standardized by the direct method according to the Chinese population structure in 2000.

${ }^{a}$ Adjusted for age and sex.

${ }^{\mathrm{b}}$ Adjusted for age.

'Differences in means were tested using an age-adjusted covariance analysis.

dLinear trends for age-specific means were tested using linear regression analyses; age group was treated as a continuous variable.

${ }^{\mathrm{e}}$ The differences are calculated as the mean for the 2007-2008 survey minus the mean for the 1998-2001 survey.

Abbreviations: BMI: body mass index.

survey ( $<<0.001) ; 81.1 \mathrm{~cm}$ vs. $83.9 \mathrm{~cm}$ in men $(\mathrm{p}<$ $0.001)$ and $74.1 \mathrm{~cm}$ vs. $75.7 \mathrm{~cm}$ in women $(\mathrm{p}<0.001)$.

Prevalence of overweight, obesity, and central obesity in Chinese adults in the 1998-2001 and 2007-2008 surveys

For the total population, only central obesity showed a significant increase in the 2007-2008 survey compared to the 1998-2001 survey (29\% increase from $17.3 \%$ to $22.4 \%, \mathrm{p}<0.001$; Figure 2). This increase was larger than the increase in prevalence of combined overweight and obesity between the two surveys. The increase in prevalence of combined overweight and obesity, of approximately $11 \%$ using the WGOC criteria (from $39.0 \%$ to $43.4 \%$ ) or approximately $10 \%$ using the WHO criteria (from 29.4 to 32.3), did not reach statistical significance.

Prevalence of overweight, obesity, and central obesity in men and women in the 1998-2001 and 2007-2008 surveys Figure 2 shows the secular changes in prevalence of overweight, obesity, and central obesity over the 10-year period. Between the 1998-2001 and 2007-2008 surveys, using the WHO criteria, the prevalence of combined overweight and obesity increased by $24 \%$ (from $31.5 \%$ to $39.1 \%, \mathrm{p}<0.001$; Figure 2) in men, but decreased by $8 \%$ (from $27.3 \%$ to $25.0 \%, \mathrm{p}<0.01$ ) in women. Using the WGOC criteria, the prevalence of combined overweight and obesity increased in men, but were not significantly different between the two surveys in women. The prevalence of central obesity increased significantly by $40 \%$ in men (from $19.5 \%$ to $27.3 \%, \mathrm{p}<0.01$; Figure 2), but the increase was non-significant in women $(15.0 \%$ to $17.1 \%$, $\mathrm{p}=0.051$ ).

The age-specific prevalence of central obesity, overweight, and obesity in men and women in the two surveys are shown in Additional file 1: Table S1.

\section{Discussion}

In 1998-2001 and in 2007-2008, we carried out two independent population-based cross-sectional surveys with similar study protocols, involving the measurement of 

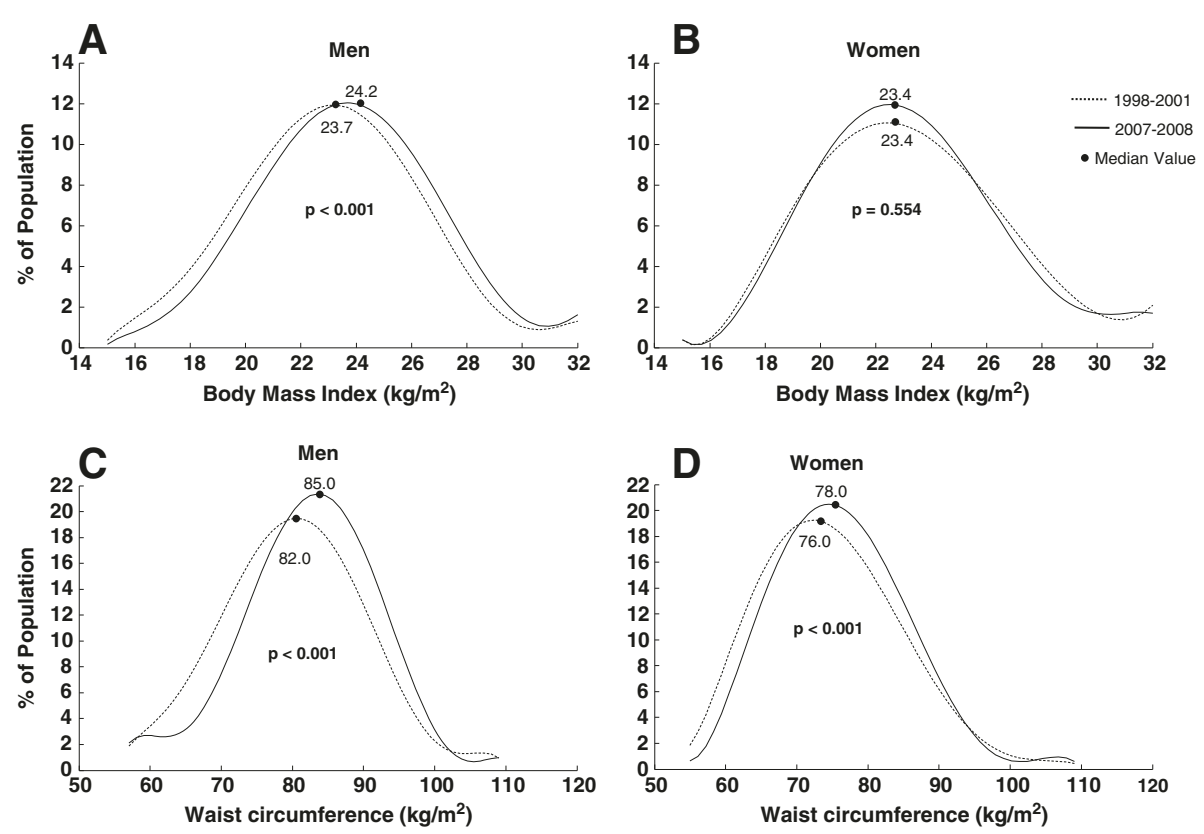

Figure 1 Smoothed frequency distribution of body mass index and waist circumference for men and women from the two surveys. The population percentage, on the $y$-axis, is plotted against BMI (Figure 1. A-B) or WC (Figure 1. C-D), on the $x$-axis. Curve fitting and loess smoothing were performed using Matalab2007a. The median figures are presented. The differences between the two surveys were tested with the Mann-Whitney U-test.

height, WC, and weight of Chinese adults, to investigate the prevalence of metabolic disorders in Shanghai. Here, WHO criteria were used for comparisons of our two surveys, and WCOG criteria were used for comparisons made between our surveys and the other nationwide Chinese surveys at the approximately same periods.

\section{Comparison of the results of our surveys with two other nationwide surveys of urban Chinese adults}

During the time period covered by our surveys, there have been two other large nationwide population-based surveys carried out in China. In 2002, the China Health and Nutrition survey examined Chinese adults in urban areas aged $\geq 18$ years [23], and in 2007-2008 the China National Diabetes and Metabolic Disorders Study [24] was conducted in Chinese adults aged $\geq 20$ years in urban areas. The nationwide prevalence of combined overweight and obesity was 37.9\% in 2002 [23] (vs. $39.0 \%$ in our study) increasing to $47.6 \%$ in $2007-2008$ (vs. $43.4 \%$ in our study) [24], using WGOC criteria. The similar trends of increased prevalence of combined overweight and obesity were observed both nationwide and in urban Shanghai. However, the prevalence of combined overweight and obesity was lower in 2007-2008 in our Shanghai population than that was reported in the 2007-2008 China National Diabetes and Metabolic Disorders Study: $43.4 \%$ vs. $47.6 \%$. In addition, the results from these two 2007-2008 reports showed that the prevalence of central obesity in the urban Shanghai population was also lower than that reported for urban Chinese adults: $22.4 \%$ vs. $30.0 \%$ [24].

Therefore, although the prevalence of central obesity in Shanghai urban population had increased over the period between our two studies, the prevalence of central obesity, and the prevalence of combined overweight and obesity is still lower than the national average at the same period.

\section{Gender differences in the prevalence of overweight,} obesity, and central obesity over the 10-year period There were obvious gender differences in the changing trends in the prevalence of combined overweight and obesity between our two studies. Between 1998-2001 and 2007-2008, the prevalence of combined overweight and obesity increased by $24 \%$ in men but decreased by $8 \%$ in women according to the WHO criteria. The prevalence of central obesity also showed a significant $40 \%$ increase in men, but there was non-significant increase in the prevalence of central obesity in women between the two studies.

Recent reports have shown that the prevalence of overweight, obesity, and central obesity among Chinese adults of both genders have increased greatly in urban and rural areas between 1993 and 2009 [2]. Our results indicate that the secular change in the prevalence of central obesity in Shanghai, the largest city in one of the most economically developed areas of southern China, was similar to that reported for the Hong Kong Chinese 
population between 1996 and 2005 [9]. This investigation showed that, although the prevalence of general obesity was steady in men but decreased in women, for central obesity, the prevalence increased in Hong Kong Chinese men and stay stable in Chinese women over a 10 year period [9]. Similar secular trends in the prevalence of obesity and central obesity have been observed among US adults [10-12].

These gender differences in obesity prevalence could be partly explained by increased exposure to drinking for men, and by the significant improvement in education level achieved by the women between the two surveys. 
This inverse association between education and obesity, which is found only in women, is described in our previous paper [25].

In addition, slower increases in the prevalence of overweight plus obesity were observed for men and women in urban Shanghai (42.9 to 51.6 and 34.9 to 34.7) compared with the national figures for urban Chinese men and women (41.4 to 55.0 and 35.3 to 40.2 ) during the same period according to the WGOC criteria $[23,24]$.

\section{Metabolic disorders in the 1998-2001 and 2007-2008 surveys}

Changes in other metabolic disorders over the 10-year period were also observed. In both men and women, after adjustment for age, there was an increase in mean fasting and 2-h glucose levels. However, mean blood pressure decreased and the lipid profiles of the population improved, with the exception of a decreased mean HDL-C level in men. Similar changes (decreased mean LDL-C levels, decreased systolic BP, and increased in HDL-C between surveys carried out in 1990 and 20012003) have been reported in a Hong Kong Chinese population [26].

\section{Advantages and limitations}

The 1998-2001 survey and the 2007-2008 survey were elaborately designed to investigate the prevalence of metabolic disorders in Shanghai using representative study sample.

Different districts were sampled in the two surveys. In the 1998-2001 survey, both districts sampled were in urban areas; in the 2007-2008 survey, four of the sampled districts were in urban areas and one district was in a suburban area. This complicates the analysis of the changes in prevalence of overweight and obesity. The changing trends in lipidemia over the 10-year period were not fully explored due to the differences in the laboratory analysis methods used in the 1998-2001 and 2007-2008 surveys.

\section{Conclusions}

Over the 10-year period covered by our surveys, there was a larger observed increase in the prevalence of central obesity than in the prevalence of combined overweight plus obesity in this urban Shanghai population. In comparison with their nationwide counterparts, this Shanghai population showed a slower growth in the prevalence of combined overweight and obesity. Significant increases in the prevalence of combined overweight and obesity, and of central obesity, were observed in men, but there was a stable or declining prevalence of combined overweight and obesity in women. Multiple community-based, gender-specific strategies are urgently required to combat the increasing prevalence of overweight and obesity in the Shanghai area.

\section{Additional file}

Additional file 1: Table S1. Standardized prevalence of overweight,

obesity and central obesity in 1998-2001 and 2007-2008.

\section{Competing interests}

The authors declare that no competing interest exists.

\section{Authors' contribution}

$\mathrm{XH}$ performed the statistical analysis and wrote the manuscript; $\mathrm{YL}$ and $\mathrm{HL}$ participated in the data collection and checked the data; $\mathrm{XM}$ and $\mathrm{CH}$ contributed to discussion; WJ and YB participated in the design of this study and edited the manuscript. All authors have read and approved the final manuscript.

\section{Acknowledgments}

This work was supported by research grants from the Key Project of Science and Technology of Shanghai (09DZ1950202), the Drug Innovation Program of National Science and Technology Project (2011ZX09307-001-02), and the Public Health Key Disciplines of Shanghai (12GWZX0104).

We thank all the following members for their contribution to this survey: Yuhua Zuo and Suying Jiang (Caoyang Community Health Center, Shanghai); Wenhong Zhong and Huilin Gu (Huayang Community Health Center,

Shanghai); Yuhua Yao (Linfen Community Health Center, Shanghai), Weizhen Shen (Pengpu Community Health Center, Shanghai), Junbin Huang (Tianmu Community Health Center, Shanghai), and Qiang Li (Gongye Community Health Center, Shanghai).

Received: 17 December 2012 Accepted: 31 October 2013

Published: 12 November 2013

\section{References}

1. Yang ZJ, Liu J, Ge JP, Chen L, Zhao ZG, Yang WY: Prevalence of cardiovascular disease risk factor in the Chinese population: the 2007-2008 China National Diabetes and Metabolic Disorders Study. Eur Heart J 2012, 33:213-220.

2. Xi B, Liang Y, He T, Reilly KH, Hu Y, Wang Q, Yan Y, Mi J: Secular trends in the prevalence of general and abdominal obesity among Chinese adults, 1993-2009. Obes Rev 2012, 13:287-296.

3. Wang Y, Mi J, Shan XY, Wang QJ, Ge KY: Is China facing an obesity epidemic and the consequences? The trends in obesity and chronic disease in China. Int J Obes (Lond) 2007, 31:177-188.

4. Klein S, Allison DB, Heymsfield SB, Kelley DE, Leibel RL, Nonas C, Kahn R: Waist circumference and cardiometabolic risk: a consensus statement from Shaping America's Health: Association for Weight Management and Obesity Prevention; NAASO, The Obesity Society; the American Society for Nutrition; and the American Diabetes Association. Am J Clin Nutr 2007, 85:1197-1202.

5. InterAct Consortium, Langenberg C, Sharp SJ, Schulze MB, Rolandsson O, Overvad K, Forouhi NG, Spranger J, Drogan D, Huerta JM, Arriola L, de Lauzon-Guillan B, Tormo MJ, Ardanaz E, Balkau B, Beulens JW, Boeing H, Bueno-de-Mesquita HB, Clavel-Chapelon F, Crowe FL, Franks PW, Gonzalez CA, Grioni S, Halkjaer J, Hallmans G, Kaaks R, Kerrison ND, Key TJ, Khaw KT, Mattiello A, et al: Long-term risk of incident type 2 diabetes and measures of overall and regional obesity: the EPIC-InterAct case-cohort study. PLoS Med 2012, 9:e1001230.

6. Van Gaal LF, Mertens IL, De Block CE: Mechanisms linking obesity with cardiovascular disease. Nature 2006, 444:875-880.

7. Nyamdorj R, Qiao Q, Lam TH, Tuomilehto J, Ho SY, Pitkaniemi J, Nakagami T, Mohan V, Janus ED, Ferreira SR: BMI compared with central obesity indicators in relation to diabetes and hypertension in Asians. Obesity (Silver Spring) 2008, 16:1622-1635.

8. Janiszewski PM, Janssen I, Ross R: Does waist circumference predict diabetes and cardiovascular disease beyond commonly evaluated cardiometabolic risk factors? Diabetes Care 2007, 30:3105-3109. 
9. Huang Z, Willett WC, Manson JE, Rosner B, Stampfer MJ, Speizer FE, Colditz GA: Body weight, weight change, and risk for hypertension in women. Ann Intern Med 1998, 128:81-88.

10. Neter JE, Stam BE, Kok FJ, Grobbee DE, Geleijnse JM: Influence of weight reduction on blood pressure: a meta-analysis of randomized controlled trials. Hypertension 2003, 42:878-884.

11. Elobeid MA, Desmond RA, Thomas O, Keith SW, Allison DB: Waist circumference values are increasing beyond those expected from BMI increases. Obesity (Silver Spring) 2007, 15:2380-2383.

12. Ko GT, Tang JS, Chan JC: Worsening trend of central obesity despite stable or declining body mass index in Hong Kong Chinese between 1996 and 2005. Eur J Clin Nutr 2010, 64:549-552.

13. Flegal KM, Carroll MD, Kit BK, Ogden CL: Prevalence of obesity and trends in the distribution of body mass index among US adults, 1999-2010. JAMA 2012, 307:491-497.

14. Flegal KM, Carroll MD, Ogden CL, Curtin LR: Prevalence and trends in obesity among US adults, 1999-2008. JAMA 2010, 303:235-241.

15. Ford ES, Li C, Zhao G, Tsai J: Trends in obesity and abdominal obesity among adults in the United States from 1999-2008. Int J Obes (Lond) 2011, 35:736-743.

16. Jia WP, Pang C, Chen L, Bao YQ, Lu JX, Lu HJ, Tang JL, Wu YM, Zuo YH, Jiang SY, Xiang KS: Epidemiological characteristics of diabetes mellitus and impaired glucose regulation in a Chinese adult population: the Shanghai Diabetes Studies, a cross-sectional 3-year follow-up study in Shanghai urban communities. Diabetologia 2007, 50:286-292.

17. Bao Y, Ma X, Li H, Zhou M, Hu C, Wu H, Tang J, Hou X, Xiang K, Jia W: Glycated haemoglobin A1c for diagnosing diabetes in Chinese population: cross-sectional epidemiological survey. BMJ 2010, 340:c2249.

18. Luepker RV, Evans A, McKeigue P, Reddy KS: Cardiovascular Survey Methods. 3rd edition. Geneva: World Health Organization; 2004

19. Obesity: preventing and managing the global epidemic. Report of a WHO consultation. World Health Organ Tech Rep Ser 2000, 894:I-xii. 1-253.

20. Zhou BF: Predictive values of body mass index and waist circumference for risk factors of certain related diseases in Chinese adults-study on optimal cut-off points of body mass index and waist circumference in Chinese adults. Biomed Environ Sci 2002, 15:83-96.

21. Joint Committee for Developing Chinese guidelines on Prevention and Treatment of Dyslipidemia in Adults: Chinese guidelines on prevention and treatment of dyslipidemia in adults. Zhonghua Xin Xue Guan Bing Za Zhi 2007, 35:390-419. in Chinese.

22. Population Census office under the State Council \& Department of Population, Social, Science and Technology Statistics National Bureau of Statistics of China (Ed): Tabulation on the 2000 population census of the people's republic of China. in national population grouped by age and gender. 1st edition. Beijing: China Statistics Press; 2002:570-572.

23. Wang LD: Nutrition and health survey of Chinese residents. Beijing: People's Medical Publishing House 2002, 2005:50-51 (in Chinese).

24. Hou XH, Lu JM, Weng JP, Ji LN, Shan ZY, Liu J, Tian HM, Ji QH, Zhu DL, Ge JP, Lin LX, Chen L, Guo XH, Zhao ZG, Li Q, Zhou ZG, Shan GL, Yang ZJ, Yang WY, Jia WP: Impact of waist circumference and body mass index on risk of cardiometabolic disorder and cardiovascular disease in Chinese adults: a national diabetes and metabolic disorders survey. PLOS One. 10.1371/journal.pone.0057319.

25. Hou X, Jia W, Bao Y, Lu H, Jiang S, Zuo Y, Gu H, Xiang K: Risk factors for overweight and obesity, and changes in body mass index of Chinese adults in Shanghai. BMC Public Health 2008, 8:389.

26. Simmons RK, Ko GT, Chan JC, Cockram CS, Nan JH, Griffin SJ: Glucose intolerance and cardiovascular risk factors in Hong Kong: data from two occupation-based cross-sectional surveys. Diabetes Res Clin Pract 2010, 90:222-227.

doi:10.1186/1471-2458-13-1064

Cite this article as: Hou et al:: Ten-year changes in the prevalence of overweight, obesity and central obesity among the Chinese adults in urban Shanghai, 1998-2007 - comparison of two cross-sectional surveys. BMC Public Health 2013 13:1064.

\section{Submit your next manuscript to BioMed Central and take full advantage of:}

- Convenient online submission

- Thorough peer review

- No space constraints or color figure charges

- Immediate publication on acceptance

- Inclusion in PubMed, CAS, Scopus and Google Scholar

- Research which is freely available for redistribution

Submit your manuscript at www.biomedcentral.com/submit
C Biomed Central 